\title{
Second Law Analysis on Ejection Cooling System
}

S.P. Liaw

Department of Mechanical and Marine Engineering National Taiwan Ocean University Keelung, Taiwan, R.O.C.

Y.H. Chang

Department of Mechanical and Marine Engineering National Taiwan Ocean University Keelung, Taiwan, R.O.C.

Follow this and additional works at: https://jmstt.ntou.edu.tw/journal

Part of the Mechanical Engineering Commons

\section{Recommended Citation}

Liaw, S.P. and Chang, Y.H. (1993) "Second Law Analysis on Ejection Cooling System," Journal of Marine Science and Technology. Vol. 1: Iss. 1, Article 5.

DOI: $10.51400 / 2709-6998.2475$

Available at: https://jmstt.ntou.edu.tw/journal/vol1/iss1/5

This Research Article is brought to you for free and open access by Journal of Marine Science and Technology. It has been accepted for inclusion in Journal of Marine Science and Technology by an authorized editor of Journal of Marine Science and Technology. 


\title{
SECOND LAW ANALYSIS ON EJECTION COOLING SYSTEM
}

\author{
S.P. Liaw and Y.H. Chang \\ Department of Mechanical and Marine Engineering \\ National Taiwan Ocean University \\ Keelung, Taiwan, R.O.C.
}

Key words: ejector, evaporator, availability, energy.

\begin{abstract}
ABSTACT
Ejection cooling system is analyzed by the second law of thermodynamics in this study. It is mainly consisted of a boiler, an ejector, an expansion device, a condenser, and an evaporator. Special focus is stressed on the variation of exergy in each component. The working refrigerant received exergy from boiler and pump and consumed in other parts of the system. The coefficients of performance based on both the first and the second laws are computed respectively and thus the changes of energy and exergy in each component of the system can be readily understood. In addition, the boiler temperature, evaporator temperature, condenser temperature, nozzle efficiency, and diffuser efficiency are varied parametrically and the results are tabulated. Finally, a compression cooling system operating at the same condition is made to compare with the present results.
\end{abstract}

\section{INTRODUCTION}

From this century on, many scholars [1-3] have engaged in researching and developing new cooling systems to overcome the weakness of conventional air-conditioner. In a conventional refrigeration cycle, it is composed of a compression device, a condenser, an expansion device, and an evaporator. Instead of a mechanical compression device, however, an ejector has recently been used to pump the refrigerant vapor. The thermodynamic mechanism of ejection cooling system is a combination of a Rankine cycle and a refrigeration cycle. The basic feature of it is to produce a suction pressure to drive the refrigeration vapor with the aid of the Rankine cycle. The components are illustrated in Fig.1. The working liquid is heated in the boiler and it enters the ejector at a state with high pressure and high temperature. In the ejector, a vacuum pressure occurs at the throat and it is possible to entrain the low-pressure vapor of refrigerant from evaporator. The mixed flow is decelerated and compressed by converting the kinetic energy into static pressure, thereafter it goes into the condenser in which heat is rejected by a circulating air or water. The liquid refrigerant leaving from the condenser flows partly through an expansion valve to the evaporator where the lower pressure liquid refrigerant is vaporized by absorbing heat from the surroundings to achieve the desired cooling effect, and partly back to the boiler through a pump to form a closed cycle. Since the ejector is driven by the high-pressure refrigerant vapor supplied from a boiler. A low grade thermal resource such as industrial waste heat or solar energy can be utilized in the boiler, thus the thermal analysis on an ejection cooling system becomes fascinating.

The analysis of available energy in each component has invoked considerable interest in these years.

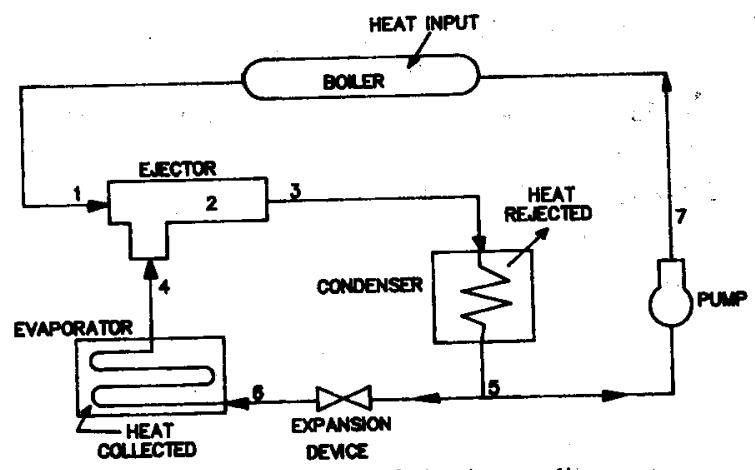

Fig. 1. Schematic diagram of ejection cooling system. 
With the aid of the second law in thermodynamics, it leads to a better understanding of the energy transfer in each process, and helps to quantify the losses clearly. The superiority of second law analysis as compared to the conventional first law analysis is mainly due to the fact that the latter does not distinguish the quality of energy, and hence assigns high quality forms of energy to low quality purpose. Second law analysis takes into account the energy conversion not only quantitatively but also qualitatively. Besides, it permits one to identify the losses occurring in different components of a system and thus improves the thermodynamic efficiency.

The second law analysis has been widely used to estimate the irreversible nature of an actual process in a system and thereby the upper bound of available energy can be readily known. The available energy is defined as the maximum work that is derivable from the interaction of an energy resource with the environment. Referring to the environmental condition, exergy or available energy is irreversibly consumed in all the components except in boiler.

Anand $e t$ al. [4] applied the second law of thermodynamics to analyze the basic irreversibilities associated with absorption cycles and the components that comprise it. Two cooling systems driven by solar energy through a mechanism of collection were studied. The understanding of the features of these irreversibilities identifies the possibility in improving the system performance. Recently, Egrican [5] has studied the absorption cooling cycles by defining two types of effectiveness for two different working fluids and the choice of working fluid was then based on this calculating results.

Second law analysis on an ammonia-sodium thiocyanate absorption refrigeration system was investigated by Tyagi [6]. The total availability received is then consumed in every part of the cycle which has been computed in order to meet an balance on available energy. Besides, in their work, the effects of temperature on available energy and coefficient of performance (COP) in each component have been studied. Very recently, Kumar et al. [7] have developed a method based on exergy to study a compression refrigeration system. Exergy-enthalpy diagrams were presented for two refrigerants, $R-11$ and $R-12$, which facilitate the analysis. Various losses occurring in components as well as the exergetic efficiency of the refrigeration cycle was calculated numerically.

In this study, an ejection cooling system powered by a heat source is analyzed. A single-component refrigerant, $R-11$ is chosen as the working fluid. The objective of this work is to investigate the effects of $T_{e} T_{c}, T_{b}, \eta_{n}$ and $\eta_{d}$ on available energy, COP, and $\mathrm{COP}_{\mathrm{a}}$ Applying the theory of the second law, the variation of available energy in each component is quantified individually. The COP and $\mathrm{COP}_{a}$ of an ejection system computed on the bases of both energy and exergy are also made to compare with those of a compression cooling system.

\section{ANALYSIS}

An ejection cooling system operating in a steady state is investigated. Based on the first law of thermodynamics, some selected refrigerants such as $R-11$, $R-12, R-113$, and $R-114$ have been employed and compared by the present authors [8]. One of the important parameters, coefficient of performance (COP), which serves as an indicator of the efficiency in a closed cycle is estimated on the basis of energy balance. The COP of a refrigeration cycle is defined as the ratio of heat absorbed by the evaporator to the sum of the heat input to boiler and pumping power.

$$
\mathrm{COP}=\frac{\text { Evaporatorduty }}{\text { Total energy input }}=\frac{\mathrm{Q}_{\mathrm{ev}}}{\mathrm{Q}_{\mathrm{b}}+\mathrm{W}_{\mathrm{p}}}
$$

The first law tells us how much the stored energy varies when a system changes from one state to another, whereas the second law tells us how much the work can be obtained. The maximum useful work can be obtained if the system eventually achieves a state at which its pressure and temperature are the same as those of the surrounding atmosphere. Hence, referring to the surroundings, the exergy or availability in a given state is defined as the maximum useful work which can be obtained from the state to exchange heat only with the atmosphere. In the absence of electrical, magnetic, and surface tension effects, the availability per unit mass is expressed as

$$
\mathrm{a}=\left(\mathrm{h}-\mathrm{h}_{\mathrm{o}}\right)-\mathrm{T}_{\mathrm{o}}\left(\mathrm{s}-\mathrm{s}_{\mathrm{o}}\right)+\mathrm{V}^{2} / 2+\mathrm{g}\left(\mathrm{z}-\mathrm{z}_{\mathrm{o}}\right)
$$

Considering the conservation of energy, the availability equation in a steady state can be derived as

$$
\sum_{j=1}^{n}\left(1-T_{0} / T_{s}\right) Q_{j}-W_{c v}+\sum_{i} m_{i} a_{i}-\sum_{e} m_{e} a_{e}-I=0
$$

The first term in the above equation accounts for the variation of availability associated with heat transfer, and $T_{s}$ is the temperature at the control surface accompanied with a heat transfer rate $Q_{j}$. The second term is the work done by the control volume. The third and fourth terms represent the changes of availability due to the fluid entering and leaving across the control surfaces respectively. The last term shows the destruction of availability, a result of an irreversible process in the decrease of useful energy which can be converted into work.

The available energy of the surroundings increases while heat is transferred from the system to it 
especially in a condensation process. No doubt the temperature of the surroundings will increase. However, the surroundings is usually very large and it maintains at a nearly uniform temperature, as a result, the change in the available part due to this heat is quite small. So the variation of exergy in surroundings can be ignored.

\section{Exergy input to the system}

In the refrigeration loop, exergy is gained in the parts of pump and boiler. Since the quality of mechanical work is $100 \%$ available energy, the exergy supplied from the pumping power is given by

$$
A_{p}=W_{p}
$$

Besides, the exergy received from the boiler in the cycle is calculated by the difference in the exergy flux between the entrance and the exit of the boiler. Referring to the numerical symbols in Fig. 1, it is

$$
A_{b}=m_{1}\left(a_{1}-a_{7}\right)
$$

Hence, the total exergy added in the whole cycle can be calculated by summing Eqs.(4) and (5).

\section{Loss of exergy}

The flow is assumed to be adiabatic and isentropic in the ejector and the expansion valve. There is no energy or heat transfer between the system and the surroundings. Therefore, the loss of availability within them is merely due to the internal irreversibilities.

The variation of available energy in every component of the loop is given by the difference in the flux of availability between the entrance and the exit. Therefore, the net loss of available energy in each component is obtained as

$$
\begin{array}{ll}
\text { Ejector: } & A=m_{1} a_{1}+m_{4} a_{4}-m_{3} a_{3} \\
\text { Condenser: } & A=m_{3}\left(a_{3}-a_{5}\right)
\end{array}
$$

Expansion valve: $A=m_{4}\left(a_{5}-a_{6}\right)$

$$
\text { Evaporator: } \quad A=m_{4}\left(a_{6}-a_{4}\right)
$$

where the subscript numbers refer to Fig.l and the mass flow rate satisfies the equality: $m_{1}+m_{4}=m_{3}$. Consequently, the coefficient of performance in the cycle based on available energy is given by

$$
\mathrm{COP}_{a}=\frac{\text { Evaporator duty }}{\text { Available exergy }}=\frac{\mathrm{Q}_{\mathrm{ev}}}{\mathrm{A}_{\mathrm{b}}+\mathrm{A}_{\mathrm{p}}}
$$

\section{RESULTS AND DISCUSSION}

During the second law analysis, the total exergy inflow is always greater than the total exergy outflow because of the existence of irreversibility. In engineering applications, it is necessary to minimize this loss. Therefore the analysis through second law in each component provides an important reference in finding where the improvement work is readily needed.

A refrigerating capacity of one ton $\left(\mathrm{Q}_{\mathrm{ev}}=200\right.$ $\mathrm{Btu} / \mathrm{min}$ ) with working fluid $R-11$ are chosen as a typical example in the following calculations. The operating condition of surroundings is set to be $77^{\circ} \mathrm{F}$ and at one atmospheric pressure. For prescribed temperatures at boiler, condenser, and evaporator, the thermodynamic properties of $R-11$ at equilibrium state in each component can be calculated. Table $\mathrm{l}(A)$ shows the temperature, pressure, mass flow rate, enthalpy, entropy, and availability at some main points of the system in the case of $\eta_{d}=0.75, \eta_{n}=0.97, \mathrm{~T}_{\mathrm{b}}=$ $221^{\circ} \mathrm{F}, \mathrm{T}_{\mathrm{c}}=95^{\circ} \mathrm{F}$, and $\mathrm{T}_{\mathrm{e}}=41^{\circ} \mathrm{F}$. As for the energy balance calculations given by the first law are listed in Table $1(B)$. No energy transfer in the ejector and the expansion valve is found.

The exergy calculations through the second law analysis are displayed in Table $1(C)$. The system obtains available energy from boiler and pump, and are consumed in other components. The loss of exergy in expansion valve is very small in magnitude when compared with those in other components. In condenser and evaporator, the energy as well as the exergy losses are caused due to the irreversible process of heat transfer across finite temperature differences. It is also noted that the loss in ejector is significant. Some reasons may be raised to explain this effect of irreversibility:

(a) a shock might occur in ejector.

(b) mixing of two flows at different temperatures.

(c) governed by two efficiencies in nozzle and diffuser.

Hence, a special focus should be stressed on the optimization of an ejector.

In Table 2, the boiler at a temperature of $203^{\circ} \mathrm{F}$ is studied. The decrease in boiler temperature results in decreasing COP, and a higher mass flow rate is needed to achieve the same cooling capacity when compared with the former case. It is especially noted that the decrease in $\mathrm{COP}_{\mathrm{a}}$ is less than $1 \%$ even though almost $10 \%$ decrease is observed in COP. This reveals the fact that the ejection cooling system is favorable in utilizing waste heat with a lower temperature level.

The temperature of condenser is set to be $86^{\circ} \mathrm{F}$ in Table 3. Both COP and $\mathrm{COP}_{\mathrm{a}}$ increase by about $20 \%$ accompanied with a lower mass flow rate. A condenser operates at a low temperature is very effective 
Table 1. Parametric study with $\eta_{d}=0.75, \eta_{n}=0.97$, $T_{b}=221^{\circ} \mathrm{F}, T_{c}=95^{\circ} \mathrm{F}$, and $T_{e}=41^{\circ} \mathrm{F}$.

A. Properties of R-11 at main points

\begin{tabular}{crrlccc}
\hline No. & \multicolumn{1}{c}{$\mathrm{T}$} & \multicolumn{1}{c}{$\mathrm{P}$} & $\mathrm{m}$ & $\mathrm{h}$ & $\mathrm{s}$ & $\mathrm{A}$ \\
1 & 221 & 131.8 & 5.4 & 117 & .192 & 17.26 \\
2 & 113 & 15.3 & 8.3 & 106 & .204 & 0.48 \\
3 & 141 & 21.5 & 8.3 & 110 & .205 & 3.30 \\
4 & 41 & 7.2 & 2.9 & 97 & .197 & -5.23 \\
5 & 95 & 21.5 & 8.3 & 28 & .057 & 0.43 \\
6 & 41 & 7.2 & 2.9 & 28 & .058 & -0.21 \\
7 & 97 & 131.8 & 5.4 & 28 & .057 & 0.65 \\
\hline
\end{tabular}

$\left(\mathrm{T}={ }^{\circ} \mathrm{F}, \mathrm{P}=\mathrm{psia}, \mathrm{m}=1 \mathrm{~b} / \mathrm{min}, \mathrm{h}=\mathrm{Btu} / \mathrm{lb}\right.$,

$\left.s=B t u / 1 b-{ }^{\circ} R, A=B t u / 1 b\right)$

B. First law analysis

\begin{tabular}{lrr}
\hline ENERGE (Btu / min) & INPUT & OUTPUT \\
BOILER & 481.49 & \\
PUMP & 1.23 & \\
EVAPORATOR & 200.00 & \\
EJECTOR & & 0.00 \\
CONDENSER & & 682.72 \\
EXPANSIONVALVE & & 0.00 \\
TOTAL & 682.72 & 682.72 \\
COP $=0.414$ & & \\
\hline
\end{tabular}

C. Second law analysis

\begin{tabular}{lrr}
\hline EXERGY (Btu/min) & INPUT & OUTPUT \\
BOILER & 89.68 & \\
PUMP & 1.23 & \\
EVAPORATOR & & 14.51 \\
EJECTOR & & 50.77 \\
CONDENSER & & 23.79 \\
EXPANSIONVALVE & & 1.83 \\
TOTAL & 90.91 & 90.91 \\
COP $_{\mathrm{a}}=2.200$ & & \\
\hline
\end{tabular}

in reducing the loss of exergy. The required energy supplied from the boiler is reduced. A system is considered to be efficient under this situation.

The effect of the temperature of evaporator is studied by setting $T_{c}=23^{\circ} \mathrm{F}$. In Table 4 , it shows an inverse effect with those of condenser temperature. Both COP and $\mathrm{COP}_{\mathrm{a}}$ decrease by $16 \%$, and the exergy loss in evaporator becomes larger. This results in a higher mass flow rate and consumes more energy in boiler.

The effect of the efficiency of diffuser is investigated in Table 5. As compared with Table 1 , the diffuser efficiency is varied from 0.75 to 0.6 . It slightly decreases both $\mathrm{COP}$ and $\mathrm{COP}_{\mathrm{a}}$. But the effect is not significant. As for nozzle efficiency, a value of 0.87 is employed instead of 0.97 in Table 1. Both COP and
Table 2. Parametric study with $\eta_{\mathrm{d}}=0.75, \eta_{\mathrm{n}}=0.97$, $T_{b}=203^{\circ} \mathrm{F} T_{c}=95^{\circ} \mathrm{F}$, and $T_{e}=41^{\circ} \mathrm{F}$.

A. Properties of R-11 at main points

\begin{tabular}{ccrcccc}
\hline No. & $\mathrm{T}$ & $\mathrm{P}$ & $\mathrm{m}$ & $\mathrm{h}$ & $\mathrm{s}$ & $\mathrm{A}$ \\
1 & 203 & 106.4 & 6.1 & 115 & .192 & 15.50 \\
2 & 109 & 15.3 & 9.0 & 106 & .202 & 0.43 \\
3 & 137 & 21.5 & 9.0 & 109 & .204 & 3.24 \\
4 & 41 & 7.2 & 2.9 & 97 & .197 & -5.23 \\
5 & 95 & 21.5 & 9.0 & 28 & .057 & 0.43 \\
6 & 41 & 7.2 & 2.9 & 28 & .058 & -0.21 \\
7 & 96 & 106.4 & 6.1 & 28 & .057 & 0.60 \\
\hline
\end{tabular}

( $\mathrm{T}={ }^{\circ} \mathrm{F}, \mathrm{P}=\mathrm{psia}, \mathrm{m}=1 \mathrm{~b} / \mathrm{min}, \mathrm{h}=\mathrm{Btu} / \mathrm{lb}$,

$\mathrm{s}=\mathrm{Btu} / 1 \mathrm{~b}-{ }^{\circ} \mathrm{R}, \mathrm{A}=\mathrm{Btu} / \mathrm{1b}$ )

B. First law analysis

\begin{tabular}{lrr}
\hline ENERGE (Btu / min) & INPUT & OUTPUT \\
BOILER & 532.14 & \\
PUMP & 1.06 & \\
EVAPORATOR & 200.00 & \\
EJECTOR & & 0.00 \\
CONDENSER & & 733.20 \\
EXPANSIONVALVE & & 0.00 \\
TOTAL & 733.20 & 733.20 \\
COP $=0.375$ & & \\
\hline
\end{tabular}

C. Second law analysis

\begin{tabular}{lrr}
\hline EXERGY (Btu / min) & INPUT & OUTPUT \\
BOILER & 90.68 & \\
PUMP & 1.06 & \\
EVAPORATOR & & 14.51 \\
EJECTOR & & 50.15 \\
CONDENSER & & 25.24 \\
EXPANSIONVALVE & & 1.83 \\
TOTAL & 91.74 & 91.74 \\
COP $_{\mathrm{a}}=2.180$ & & \\
\hline
\end{tabular}

$\operatorname{COP}_{a}$ decrease as shown in Table 6. However, the exergy loss is increased by $13 \%$ and this is recommended as the first priority to do the optimization work.

It is interesting to compare the present study with a traditional compression cooling system. The compression cooling system uses a compressor instead of a boiler and an ejector. Assuming the same pressure and temperature as those in Table 2, the temperature at condenser entrance can be calculated following a polytropic process. At last the mass flow rate as well as the required power of compressor can be computed. Since all the work done by compressor is taken as available energy, the final results show that both $\mathrm{COP}$ and $\mathrm{COP}_{\mathrm{a}}$ are equal to 1.205. However, For an ejection cooling system, the values were 0.375 and 
Table 3. Parametric study with $\eta_{\mathrm{d}}=0.75, \eta_{\mathrm{n}}=0.97$, $T_{b}=203^{\circ} \mathrm{F} T_{c}=95^{\circ} \mathrm{F}$, and $T_{e}=41^{\circ} \mathrm{F}$.

A. Properties of R-11 at main points

\begin{tabular}{crrcccc}
\hline No. & \multicolumn{1}{c}{ T } & P & m & h & s & A \\
1 & 221 & 131.8 & 4.4 & 117 & .192 & 17.26 \\
2 & 109 & 13.3 & 7.3 & 106 & .205 & -0.65 \\
3 & 134 & 18.2 & 7.3 & 109 & .206 & 1.98 \\
4 & 41 & 7.2 & 2.9 & 97 & .197 & -5.23 \\
5 & 86 & 18.2 & 7.3 & 26 & .054 & 1.98 \\
6 & 41 & 7.2 & 2.9 & 26 & .054 & -0.07 \\
7 & 87 & 131.8 & 4.4 & 26 & .054 & 0.61 \\
\hline
\end{tabular}

( $\mathrm{T}={ }^{\circ} \mathrm{F}, \mathrm{P}=\mathrm{psia}, \mathrm{m}=1 \mathrm{~b} / \mathrm{min}, \mathrm{h}=\mathrm{Btu} / \mathrm{lb}$, $\left.\mathrm{s}=\mathrm{Btu} / \mathrm{1b}-{ }^{\circ} \mathrm{R}, \mathrm{A}=\mathrm{Btu} / \mathrm{1b}\right)$

B. First law analysis

\begin{tabular}{lrr}
\hline ENERGE (Btu / min) & INPUT & OUTPUT \\
BOILER & 404.67 & \\
PUMP & 1.03 & \\
EVAPORATOR & 200.00 & \\
EJECTOR & & 0.00 \\
CONDENSER & & 605.70 \\
EXPANSION VALVE & & 0.00 \\
TOTAL & 605.70 & 605.70 \\
COP $=0.493$ & & \\
\hline
\end{tabular}

C. Second law analysis

\begin{tabular}{lrr}
\hline EXERGY (Btu / min) & INPUT & OUTPUT \\
BOILER & 74.03 & \\
PUMP & 1.03 & \\
EVAPORATOR & & 14.51 \\
EJECTOR & & 47.63 \\
CONDENSER & & 11.66 \\
EXPANSIONVALVE & & 1.26 \\
TOTAL & 75.06 & 75.06 \\
COP $_{\mathrm{a}}=2.665$ & & \\
\hline
\end{tabular}

2.18 for $\mathrm{COP}$ and $\mathrm{COP}_{\mathrm{a}}$ respectively. So it is obvious that the compression system is better than the ejection system on the basis of first law. On the contrary, the ejection cooling system is superior to the compression system with the aid of a second law analysis. The first law does not distinguish the quality of energies (heat and work), but the second law analysis takes into account not only the quantity of energy consumed but also the quality of energy conversion. Hence, it would be more appropriate to analyze the system on the basis of available energy especially in utilizing a low grade heat source.

\section{CONCLUSIONS}

From the above analyses, several conclusions
Table 4. Parametric study with $\eta_{\mathrm{d}}=0.75, \eta_{\mathrm{n}}=0.97$, $T_{b}=221^{\circ} \mathrm{F} T_{c}=95^{\circ} \mathrm{F}$, and $T_{c}=23^{\circ} \mathrm{F}$.

A. Properties of R-11 at main points

\begin{tabular}{crrlccc}
\hline No. & \multicolumn{1}{c}{ T } & P & m & h & s & \multicolumn{1}{c}{ A } \\
1 & 221 & 131.8 & 6.4 & 117 & .192 & 17.26 \\
2 & 110 & 14.8 & 9.4 & 106 & .203 & 0.21 \\
3 & 141 & 21.5 & 9.4 & 110 & .205 & 3.30 \\
4 & 23 & 4.7 & 3.0 & 95 & .198 & -8.29 \\
5 & 95 & 21.5 & 9.4 & 28 & .057 & 0.43 \\
6 & 23 & 4.7 & 3.0 & 28 & .059 & -0.73 \\
7 & 96 & 131.8 & 6.4 & 28 & .057 & 0.65 \\
\hline
\end{tabular}

( $\mathrm{T}={ }^{\circ} \mathrm{F}, \mathrm{P}=\mathrm{psia}, \mathrm{m}=1 \mathrm{~b} / \mathrm{min}, \mathrm{h}=\mathrm{Btu} / \mathrm{lb}$,

$\mathrm{s}=\mathrm{Btu} / 1 \mathrm{~b}-{ }^{\circ} \mathrm{R}, \mathrm{A}=\mathrm{Btu} / 1 \mathrm{~b}$ )

B. First law analysis

\begin{tabular}{lrr}
\hline ENERGE $($ Btu / min) & INPUT & OUTPUT \\
BOILER & 573.57 & \\
PUMP & 1.46 & \\
EVAPORATOR & 200.00 & \\
EJECTOR & & 0.00 \\
CONDENSER & & 775.03 \\
EXPANSIONVALVE & & 0.00 \\
TOTAL & 775.03 & 775.03 \\
COP $=0.348$ & & \\
\hline
\end{tabular}

C. Second law analysis

\begin{tabular}{lrr}
\hline EXERGY $(\mathrm{Btu} / \mathrm{min})$ & INPUT & OUTPUT \\
BOILER & 106.83 & \\
PUMP & 1.46 & \\
EVAPORATOR & & 22.51 \\
EJECTOR & & 55.28 \\
CONDENSER & & 27.04 \\
EXPANSIONVALVE & & 3.46 \\
TOTAL & 108.29 & 108.29 \\
COP $_{\mathrm{a}}=1.847$ & & \\
\hline
\end{tabular}

are made:

1. The changes in $\mathrm{COP}$ and $\mathrm{COP}_{\mathrm{a}}$ due to different operating conditions play important roles in the optimization of a whole system.

2. Both COP and $\mathrm{COP}_{\mathrm{a}}$ increase with evaporator temperature, boiler temperature, nozzle efficiency, and diffuser efficiency, whereas they decrease with increasing condenser temperature.

3. Most exergy loss occurs in ejector, evaporator, and condenser.

4. The nozzle efficiency has a significant influence on ejector performance.

5. A second law analysis is more realistic in the performance evaluation of individual compo- 
Table 5. Parametric study with $\eta_{d}=0.60, \eta_{n}=0.97$, $T_{b}=221^{\circ} \mathrm{F} T_{c}=95^{\circ} \mathrm{F}$, and $T_{c}=41^{\circ} \mathrm{F}$.

A. Properties of R-11 at main points

\begin{tabular}{crrlccc}
\hline No. & T & \multicolumn{1}{c}{ P } & m & \multicolumn{1}{c}{ h } & s & \multicolumn{1}{c}{ A } \\
1 & 221 & 131.8 & 5.8 & 117 & .192 & 17.26 \\
2 & 118 & 16.7 & 8.7 & 107 & .203 & 1.15 \\
3 & 143 & 21.5 & 8.7 & 110 & .206 & 3.33 \\
4 & 41 & 7.2 & 2.9 & 97 & .197 & -5.23 \\
5 & 95 & 21.5 & 8.7 & 28 & .057 & 0.43 \\
6 & 41 & 7.2 & 2.9 & 28 & .058 & -0.21 \\
7 & 97 & 131.8 & 5.8 & 28 & .057 & 0.65 \\
\hline
\end{tabular}

$\left(\mathrm{T}={ }^{\circ} \mathrm{F}, \mathrm{P}=\mathrm{psia}, \mathrm{m}=1 \mathrm{~b} / \mathrm{min}, \mathrm{h}=\mathrm{Btu} / \mathrm{b}\right.$,

$\mathrm{s}=\mathrm{Btu} / 1 \mathrm{~b}-{ }^{\circ} \mathrm{R}, \mathrm{A}=\mathrm{Btu} / 1 \mathrm{~b}$ )

B. First law analysis

\begin{tabular}{lrr}
\hline ENERGE (Btu / min) & INPUT & OUTPUT \\
BOILER & 513.95 & \\
PUMP & 1.31 & \\
EVAPORATOR & 200.00 & \\
EJECTOR & & 0.00 \\
CONDENSER & & 715.26 \\
EXPANSIONVALVE & & 0.00 \\
TOTAL & 715.26 & 715.26 \\
COP $=0.338$ & & \\
\hline
\end{tabular}

C. Second law analysis

\begin{tabular}{lrr}
\hline EXERGY (Btu / min) & INPUT & OUTPUT \\
BOILER & 95.73 & \\
PUMP & 1.31 & \\
EVAPORATOR & & 14.52 \\
EJECTOR & & 55.57 \\
CONDENSER & & 25.12 \\
EXPANSIONVALVE & & 1.83 \\
TOTAL & 97.04 & 97.04 \\
COP $_{\mathrm{a}}=2.061$ & & \\
\hline
\end{tabular}

nent.

\section{NOMENCLATURE}

$\begin{array}{ll}\text { A } & \text { availability flow rat } \\ \text { a } & \text { availability per un } \\ \text { COP } & \text { coefficient of perf } \\ \text { COP } & \text { coefficient of perf } \\ \text { h } & \text { enthalpy } \\ \text { m } & \text { mass flow rate } \\ \text { P } & \text { pressure } \\ \text { Q } & \text { heat transfer rate } \\ \text { s } & \text { entropy } \\ \text { T } & \text { temperature } \\ \text { V } & \text { velocity }\end{array}$

Table 6. Parametric study with $\eta_{d}=0.75, \eta_{n}=0.87$, $T_{b}=221^{\circ} \mathrm{F} T_{c}=95^{\circ} \mathrm{F}$, and $T_{e}=41^{\circ} \mathrm{F}$.

A. Properties of R-11 at main points

\begin{tabular}{crrlccc}
\hline No. & \multicolumn{1}{c}{$\mathrm{T}$} & \multicolumn{1}{c}{$\mathrm{P}$} & $\mathrm{m}$ & $\mathrm{h}$ & $\mathrm{s}$ & \multicolumn{1}{c}{$\mathrm{A}$} \\
1 & 221 & 131.8 & 5.8 & 117 & .192 & 17.26 \\
2 & 119 & 15.3 & 9.4 & 107 & .205 & 0.54 \\
3 & 147 & 21.5 & 9.4 & 111 & .207 & 3.39 \\
4 & 41 & 7.2 & 2.9 & 97 & .197 & -5.23 \\
5 & 95 & 21.5 & 9.4 & 28 & .057 & 0.43 \\
6 & 41 & 7.2 & 2.9 & 28 & .058 & -0.21 \\
7 & 97 & 131.8 & 6.5 & 28 & .057 & 0.65 \\
\hline
\end{tabular}

$\left(\mathrm{T}={ }^{\circ} \mathrm{F}, \mathrm{P}=\mathrm{psia}, \mathrm{m}=1 \mathrm{~b} / \mathrm{min}, \mathrm{h}=\mathrm{Btu} / \mathrm{b}\right.$, $\left.\mathrm{s}=\mathrm{Btu} / 1 \mathrm{~b}-{ }^{\circ} \mathrm{R}, \mathrm{A}=\mathrm{Btu} / \mathrm{lb}\right)$

B. First law analysis

\begin{tabular}{lrr}
\hline ENERGE (Btu / min) & INPUT & OUTPUT \\
$\quad$ BOILER & 580.67 & \\
PUMP & 1.48 & \\
EVAPORATOR & 200.00 & \\
EJECTOR & & 0.00 \\
CONDENSER & & 782.15 \\
EXPANSION VALVE & & 0.00 \\
TOTAL & 782.15 & 782.15 \\
COP $=0.344$ & & \\
\hline & & \\
C. Second law analysis & & \\
\hline EXERGY (Btu / min) & INPUT & OUTPUT \\
$\quad$ BOILER & 108.15 & \\
PUMP & 1.48 &. \\
EVAPORATOR & & 14.51 \\
$\quad$ EJECTOR & & 65.42 \\
CONDENSER & & 27.87 \\
$\quad$ EXPANSIONVALVE & & 1.83 \\
TOTAL & 109.63 & 109.63 \\
COP $=1.824$ & & \\
\hline
\end{tabular}

W work

$\eta \quad$ efficiency

\section{Subcripts}

$\begin{array}{ll}\text { b } & \text { boiler } \\ \text { cv } & \text { control volume } \\ \text { d } & \text { diffuser } \\ \text { e } & \text { exit } \\ \text { ev } & \text { evaporator } \\ \text { i } & \text { inlet } \\ \text { n } & \text { nozzle } \\ \text { o } & \text { surroundings } \\ \text { p } & \text { pump }\end{array}$


Table 7. Vapour compression cycle with work fluid R-11

(1) Evaporator temperature $T_{e}=41^{\circ} F\left(5^{\circ} \mathrm{C}\right)$

(2) Condenser temperature $T_{c}=95^{\circ} \mathrm{F}\left(35^{\circ} \mathrm{C}\right)$

(3) Mass flow rate of refrigerant $=2.8876 \mathrm{1b} / \mathrm{min}$ per ton of refrigeration

\begin{tabular}{ccccccc}
\hline POINT & $\mathrm{T}\left({ }^{\circ} \mathrm{F}\right)$ & $\mathrm{P}(\mathrm{PSIA})$ & M.F.R. $(\mathrm{LB})$ & $\mathrm{h}(\mathrm{BTU} / \mathrm{LB})$ & $\mathrm{s}\left(\mathrm{BTU} / \mathrm{LB}{ }^{\circ} \mathrm{R}\right)$ & $\mathrm{A}(\mathrm{LB} / \mathrm{BTU})$ \\
1 & 41.00 & 7.184 & 2.8876 & 96.91 & 0.1965 & -5.2331 \\
2 & 98.34 & 21.454 & 2.8876 & 105.43 & 0.1953 & 4.9354 \\
3 & 95.00 & 21.454 & 2.8876 & 104.20 & 0.1951 & 3.0353 \\
4 & 95.00 & 21.454 & 2.8876 & 27.65 & 0.0570 & 0.5414 \\
5 & 41.00 & 7.184 & 2.8876 & 27.65 & 0.0582 & -0.2074
\end{tabular}

Exergy balance for compression system

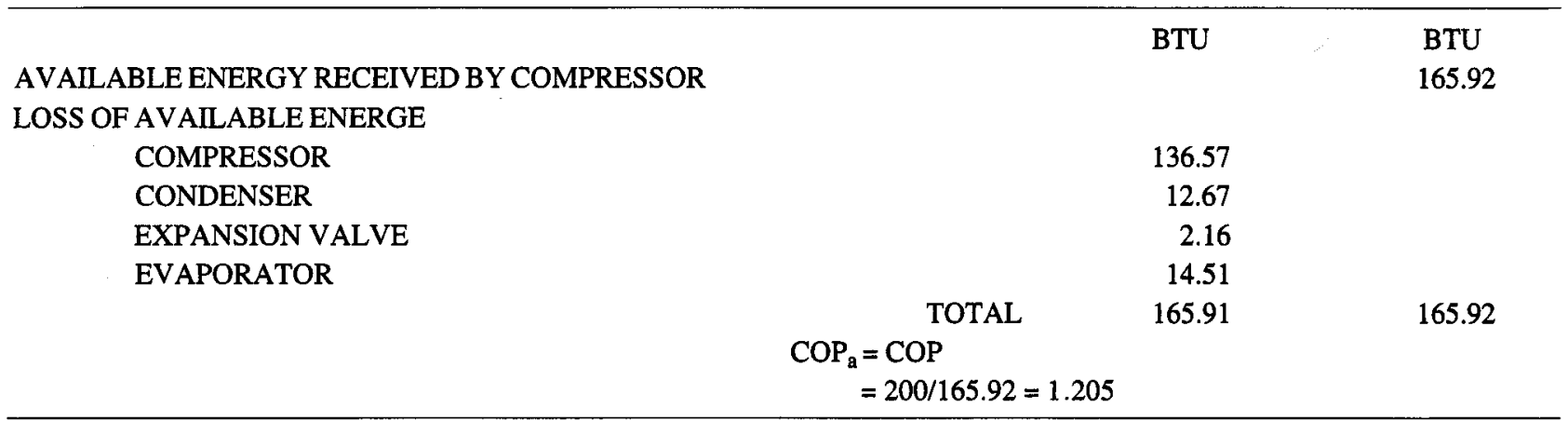

\section{REFERENCES}

1. K.M. Hamner, "An Investigation of an EjectorCompression Refrigeration Cycle and Its Applications to Heating, Cooling, and Energy Conservation," Ph.D. thesis, University of Alabama, Birmingham, USA (1978).

2. L.T. Chen, "A Heat Driven Mobile Refrigeration Cycle Analysis," Energy Convers, Vol.18, No.l, pp.25-29 (1978).

3. C. Thupvongsa, "Investigation of an Ejector Heat Pump," Ph.D. thesis, University of New Mexico, Albuquerque, USA (1978).

4. D.K. Anand, K.W. Lindler, S. Schweitzer, and W.J. Kennish, "Second Law Analysis of Solar Powered Absorption Cooling Cycle and System," J. of Solar Energy Engineering, ASME. Vol.106, pp.291-298, (1984).

5. N. Egrican, "The Second Law Analysis of Absorption Cooling Cycles," Heat Recovery System \& CHP, Vol.8, No.6, pp.549-558, (1988).

6. K.P. Tyagi, "Second Law Analysis of NH3NaSCN Absorption Refrigeration Cycle," Heat Recovery System, Vol.6, No.1, pp.72-82, (1986).

7. S. Kumar, M. Prevost and R. Bugarel, "Exergy Analysis of A Compression Refrigeration system," Heat Recovery System \& CHP, Vol.9, No.1, pp.151$157,(1989)$.
8. Y.H. Chang, S.P. Liaw, and W. H. Huang, "Perfor mance Analysis on Ejection Cooling System," Tatung Journal, Vol.20, pp.91-99, (1990). 